
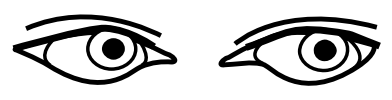

\title{
1913 års pensionsförsäkring - den första allmänna socialförsäkringen
}

\author{
PER GUNNAR EDEBALK
}

För ett hundra år sedan dvs. 1913 infördes en allmän pensionsförsäkring i Sverige. Det var världens första universella socialförsäkring. Beslutet kan ses som det första steget in i den svenska välfärdsstaten.

Den 21 maj 1913 fattade den svenska riksdagen beslut om att införa en allmän pensionsförsäkring. Denna var den första socialförsäkringen i världen som omfattade (i stort sett) hela befolkningen. Pensionsförsäkringen angav också vägen för fortsatta reformer inom socialförsäkringen. 1913 års beslut har därför stor principiell betydelse.

I denna artikel skall jag belysa bakgrunden till 1913 års beslut och ge en förklaring

Per Gunnar Edebalk är professor och verksam vid Socialhögskolan, Lunds universitet. till varför försäkringen fick sin speciella utformning. Jag kommer också att visa att 1913 års beslut blev inledningen till ett systemskifte inom den svenska socialpolitiken.

\section{Bakgrunden}

Kring förra sekelskiftet var det vanligt att äldre bodde tillsammans med sina barn, något som byggde på lag och tradition. Behövande gamlingar, som saknade privata alter- 
nativ, hade att förlita sig på den kommunala fattigvården. Fattigvården reglerades genom 1871 års fattigvårdsförordning, som anses vara den strängaste fattigvårdsförordning som funnits i Sverige. Missförhållanden inom den tidens fattigvård var påtagliga och uppmärksammade (Edebalk 1996).

Vid den här tiden hade Sverige något över fem miljoner invånare och den övervägande majoriteten bodde på landsbygden. Det fanns mer än 2400 kommuner, de allra flesta var landsbygdskommuner. Den pågående industrialiseringen och urbaniseringen innebar att många landsbygdskommuner också var utflyttningskommuner med relativt sett många åldringar. Gamla och orkeslösa var den största gruppen understödstagare inom fattigvården.

Sverige hade den högsta andelen åldringar bland någorlunda jämförbara länder och andelen åldringar (65+) hade ökat kraftigt under andra halvan av 1800-talet. Andelen äldre av befolkningen ökade från närmare fem procent år 1850 till över åtta procent år 1900. Bl.a. minskad barnadödlighet i början av 1800-talet och emigrationen i slutet av århundradet ligger bakom denna utveckling. Utvecklingen ledde till en stark press på fattigvården i många kommuner.

Fattigvården svarade för ungefär en fjärdedel av landsbygdskommunernas utgifter. En annan relativt stor utgiftspost var sockenkyrkan och prästlöner. Den största posten var emellertid utgifterna för den obligatoriska folkskolan. Framför allt kom utgifterna för fattigvården och skolan att öka och från 1880 till början av 1900-talet ungefärligen, fördubblades landsbygdskommunernas utgifter (Edebalk \& Olsson
2011). De ökade utgifterna krävde höjda skatter. Skattekraften var ytterst ojämn bland kommunerna och högskattekommuner kunde ha fem eller sex gånger så höga skatter som lågskattekommuner. Skattetrycket i många landsbygdskommuner blev helt olidligt.

Ojämnheten i den kommunala skattebördan hade en tendens att öka. Därför började man omkring år 1900 att på allvar diskutera olika reformförslag (Edebalk \& Olsson 2011). Vissa debattörer menade att den enklaste vägen var att staten tog över utgifterna för folkskolan och kyrkliga ändamål. Dessa uppgifter var ju till sin karaktär statliga och bestämda av staten. Också allt starkare röster började höjas för en skatteutjämning eller för statsbidrag till de fattigaste kommunerna. Men frågan om skatteutjämning eller statsbidrag möttes av motstånd från starka intressenter, dvs. de som skulle betala (Andersson 1985).

Utgifterna för fattigvården var mycket ojämnt fördelade och detta kom också att uppmärksammas både i och utanför riksdagen. Någon form av utjämning borde ske, menade man. Frågan kom bl.a. på riksdagens bord år 1911. Enligt riksdagens mening skulle ålderdomspensionering bli det kraftigaste medlet för att åstadkomma en skatteutjämning (AK:s femte tillfälliga utskotts utlåtande 1911:8).

\section{Pensionsförsäkringen}

Att en ålderdomspensionering skulle kunna avlasta fattigvården hade noterats redan 1884 i riksdagen, då pensionsfrågan för första gången fick sin politiska aktualitet 
genom liberalen Adolf Hedins riksdagsmotion (Motion 1884:11). Hedins motion gällde olycksfalls- och ålderdomsförsäkring för arbetare och den var inspirerad av de arbetarförsäkringar som då höll på att genomföras i Tyskland under järnkanslern Bismarcks ledning. Den tidens Tyskland var föregångslandet inom det vi i dag kallar socialförsäkringar.

Adolf Hedins motion fick ett relativt gott bemötande i riksdagen och efter riksdagsbehandlingen kom utredandet $\mathrm{i}$ gång. Två statliga utredningar kom att behandla pensionsfrågan före sekelskiftet, dock utan positivt resultat (Elmér 1960). I början av 1900-talet kom pensionsfrågan på nytt upp på den politiska dagordningen och samtliga större partier visade nu ett positivt intresse för en lösning, något som bl.a. framgår av valprogrammen (Håkansson 1952).

År 1906 arrangerades en stor fattigvårdskongress i Stockholm med närmare 1000 deltagare (Palmstierna 1907). Kongressen för fattigvård och folkförsäkring, som var det officiella namnet, antyder ett samband mellan socialförsäkringar och fattigvård. Av möjliga socialförsäkringar sågs främst en pensionsförsäkring som ett medel att minska fattigvårdsutgifterna. Kongressen uttalade sig för en utredning och år 1907 tillsatte den då konservativa regeringen den s.k. Ålderdomsförsäkringskommittén.

Ålderdomsförsäkringskommittén avlämnade ett betänkande i slutet av år 1912 (Ålderdomsförsäkringskommittén 1912). Regerings- och riksdagsbehandlingen blev snabb och det slutliga beslutet togs i maj 1913 av en stor majoritet i riksdagen (Proposition 1913:126).
Den allmänna pensionsförsäkringen omfattade i stort sett hela befolkningen, undantagna var ordinarie statstjänstemän och präster, som hade egna pensionssystem. Pension skulle utgå till den som var oförmögen till arbete p.g.a. invaliditet eller som uppnått 67 års ålder. Försäkringen bestod av två delar:

1. En avgiftspension finansierad med egenavgifter, som utgick efter taxerad inkomst. Grundavgiften för dem som inte hade inkomst var tre kronor om året och maximal avgift var 13 kronor om året. Den årliga avgiftspensionen skulle bli 30 procent av inbetalda pensionsavgifter för män och 24 procent för kvinnor.

2. En skattefinansierad inkomstprövad tilläggspension, som skulle ge ett tillägg till avgiftspensionen. Tilläggspensionen hade till syfte att snabbt få bort invalider och åldringar från fattigvården. Maximalt belopp var 150 kronor om året för män och 140 kronor för kvinnor. Som jämförelse kan nämnas att genomsnittslönen för en industriarbetare var ungefär 1300 kronor om året (Elmér 1960).

Att avgiftspensionen och tilläggspensionen var högre för män än för kvinnor motiverades med att kvinnor hade en genomsnittligt längre livstid än män. Ett inte orimligt antagande är att särbehandlingen av kvinnor sammanhänger med att den allmänna rösträtten då endast omfattade män.

Den allmänna pensionsförsäkringen i Sverige var den första socialförsäkringen i världen som i princip omfattade hela befolkningen. I de förslag som funnits med 
i bilden sedan 1880-talet kan man urskilja tre alternativa huvudmodeller. Den ena var en statssubventionerad frivillig pensionsförsäkring, som fanns i några länder. Erfarenheten hade emellertid visat att en frivillig försäkring fick en obetydlig omfattning och att det inte var de mest behövande som försäkrade sig. En frivillig pensionsförsäkring var därför inte aktuell i Sverige.

I länder som infört pensionssystem fanns två andra huvudmodeller. Den första är den tyska modellen, som införts 1889 och som ingick i Bismarcks arbetarförsäkringar. Den försäkringen omfattade arbetare och finansierades (med visst statligt stöd) genom arbetsgivaravgifter och egenavgifter. Den tyska modellen var försäkringsmässig. Den andra var den danska modellen från 1891, som var ett försörjningssystem med schabloniserade ersättningar utan fattigvårdskaraktär. Den danska pensionen var skattefinansierad och utgick efter inkomstprövning.

Under de närmare tre decennier som förflutit sedan Hedin aktualiserade pensionsfrågan hade Sverige genomgått en snabb ekonomisk utveckling. Den industriella tillväxten var stark, särskilt från 1890talet. Industriarbetarna hade organiserat sig fackligt och politiskt och krävde bl.a. sociala rättigheter i stället för den förnedrande kommunala fattigvården. Den ekonomiska utvecklingen följdes av sociala och politiska förändringar och 1911 debuterade allmän rösträtt för män. Den här i korthet beskrivna utvecklingen kan bidra till att förklara att ett pensionssystem infördes i Sverige. Men varför valdes en modell med universell avgiftspension och inte någon av de ovan angivna modellerna?
Då det gäller påverkan på tidiga socialpolitiska beslut hänvisas ofta till Sveriges agrara struktur (se t.ex. Baldwin 1990, Elmér 1960 och Esping-Andersen 1985). De svenska bönderna hade ett starkt politiskt inflytande och vid tiden för beslutet 1913 var 45 procent av riksdagens ledamöter jordbrukare (Sköld \& Halvarson 1966). Viktigt är också att det socialdemokratiska partiet vid den här tiden önskade bredda sin väljarbas och appellera till landsbygdens "småfolk". Många äldre på landsbygden skulle inte omfattas i en tysk modell och bönderna var ovilliga att betala arbetsgivaravgifter för sina drängars och pigors pensionering. Landsbygdsintressena kunde följaktligen inte acceptera den tyska lösningen.

En annan faktor att beakta är den speciella demografiska situationen i Sverige med relativt många åldringar att försörja. En tredje faktor är finansieringsmöjligheterna. Allt annat lika skulle en pensionslösning i Sverige bli dyrare än i andra länder p.g.a. den demografiska situationen. En dansk modell, med renodlad skattefinansiering, blev därför svår att acceptera.

En ny finansieringsmöjlighet kom med inkomstskatten och som Sverige utvecklades ekonomiskt, blev inkomster ett skatteobjekt. År 1902 infördes en statlig progressiv inkomstskatt. Härmed kom också inkomstdeklarationen. Då kunde skatter och egenavgifter baserade på inkomst fastställas. Här öppnades en helt ny finansieringsmöjlighet, som inte fanns med i de tidigare pensionsdiskussionerna. De nya egenavgifterna tillsammans med den skattefinansierade tilläggspensionen skulle ge en viss utjämning av fattigvårdskostnaderna mellan kommunerna. Detta blev 
alltså en tidig form av interkommunal skatteutjämning.

Historikern Anders Berge har utifrån en annan utgångspunkt behandlat egenavgifterna inom pensionsförsäkringen (Berge 1995). För Berge representerade egenavgiften en form av statlig normsättning: arbetsamhet, ordnad livsföring och skötsamhet skulle belönas. Berges analys är intressant och visst kan man se egenavgifterna i ett uppfostringsperspektiv. Men enligt min mening är det mest rimligt att se de obligatoriska avgifterna som en ny skatt och detta i en tid när en ny möjlighet uppenbarade sig, nämligen skatt på taxerad inkomst. Denna öronmärkta skatt blev legitim genom att folk såg vad den skulle användas till, dvs. att på lång sikt ge en pension och att avlasta de mest fattigvårdstyngda kommunerna.

1913 års reform var principiellt betydelsefull även om ersättningarna var blygsamma. Högsta tilläggspensionen för män, 150 kronor om året, svarar i dagens penningvärde mot cirka 6700 kronor om året, dvs. mot ungefärligen 560 kronor i månaden. Härtill kom att de som vid lagens ikraftträdande redan fyllt 67 år uteslöts från pensionsersättning. Till en början var alltså pensionsförsäkringen allmän endast då det gäller avgiftsbetalandet.

Avgiftspensionen skulle ge rimliga pensioner först i en mycket avlägsen framtid. I realiteten blev det därför tilläggspensionen som fick någon socialpolitisk betydelse. Den var dock otillräcklig för många och enligt en undersökning avseende år 1923 fick 17 procent av pensionstagarna pensionen kompletterad med fattigvård; i storstäderna inte mindre än 33 procent (SOU
1925:8). I sina huvuddrag gällde 1913 års beslut fram till mitten av 1930-talet, då kvinnor och män jämställdes och själva försäkringsdelen tonades ner. Utvecklingen fullbordades genom beslutet om folkpension 1946 (Proposition 1946:220). Folkpensionen utgick med ett enhetsbelopp till alla som fyllt 67 år och den kom att definitivt befria åldringar från fattigvården .

\section{Enighet och oenighet}

Inom dåtidens politiska partier fanns en stor enighet vid beslutet år 1913. Det var en högerregering med civilminister Hugo Hamilton som hade tillsatt Ålderdomsförsäkringskommittén. Socialdemokraternas ledare Hjalmar Branting var aktiv i utredningen och likaledes aktiv i att genomdriva ett beslut i riksdagen. Propositionen till rikdagen utarbetades av den liberale civilministern Axel Schotte. Den stora enigheten mellan och inom de politiska partierna betyder emellertid inte att det saknades kritik mot reformen.

Inom socialdemokraternas vänstra flygel menade man exempelvis att försäkringen gav alldeles för små pensioner (Elmér 1960). Detta var en relevant invändning, men företrädarna menade att förbättringar skulle komma och att 1913 års beslut endast var det första steget. Givetvis fanns också kritik mot att män och kvinnor inte behandlades lika. Det fanns också invändningar mot att arbetsgivarna slapp betala avgifter. De som företrädde denna syn menade att pensionsförsäkringen skulle vara en arbetarförsäkring liknande den i Tyskland. 
Den allra häftigaste oppositionen kom från det s.k. "fattigvårdsfolket", som utgjorde kärnan i Centralförbundet för socialt arbete, CSA, och som hade arrangerat 1906 års fattigvårdskongress. Fattigvårdsfolket tillhörde Stockholmsområdets ledande ekonomiska och kulturella skikt och deras socialpolitiska grundsyn kan närmast betraktas som socialliberal och paternalistisk (Lundquist 1997). Att avskaffa fattigdom såg fattigvårdsfolket ytterst som ett uppfostringsproblem.

Så snart Ålderdomsförsäkringskommittén publicerat sitt betänkande i november 1912 startade fattigvårdsfolket en häftig kampanj mot förslaget (Edebalk 1996). De reagerade med våldsam frenesi för att påverka den allmänna opinionen, regeringen och riksdagen.

Fattigvårdsfolket hade inga invändningar mot avgiftspensionen. Kritiken gällde tillläggspensionen och invändningarna mot denna baserades på deras uppfostringsideologi. Den inkomstprövade pensionen var inget annat än ett understöd, som skulle minska arbetsviljan och folks sparsamhet. Dessutom skulle folk vänja sig vid understöd (utan motprestation) och även "ovärdiga" skulle på så sätt få pension. Till "ovärdiga" hörde alkoholister, försumliga familjeförsörjare och andra som visat asocialt beteende. Enligt fattigvårdsfolket borde sådana understöd endast utgå efter individuell behovsprövning och det skulle vara en uppgift för fattigvården.

Fattigvårdsfolket nådde några smärre segrar genom att vissa "värdighetsbestämmelser" infördes vilka bl.a. uteslöt den som förde ett asocialt levnadssätt. Sådana personer kunde alltså förvägras tilläggspen- sion. Men grundstrukturen i den allmänna pensionsförsäkringen förblev intakt.

\section{Systemskiftet}

Genom pensionsbeslutet 1913 påbörjades ett systemskifte (Borg 2004). Grunden till socialförsäkringens utveckling var lagd och den skulle reducera behovet av fattigvård och den ekonomiska situationen för många kommuner skulle förbättras. Härtill kom att fattigvården ansågs vara kränkande och den trädde in först då personer hamnat i en nödsituation. Socialförsäkringen skulle ge en starkare rättighet till ersättning och den var också preventiv, dvs. den gav ett skyddsnät som innebar att man inte måste göra sig fattig för att få ersättning. Företrädarna för denna ideologi vann en förkrossande seger över fattigvårdsfolket inför 1913 års beslut. Även om den allmänna pensionsförsäkringen hade sina brister och blygsamma ersättningar så blev färdvägen utstakad.

År 1916 fattade riksdagen beslut om olycksfallsförsäkring (en yrkesskadeförsäkring), också detta efter förslag från Ålderdomsförsäkringskommittén. Denna var då den kanske modernaste yrkesskadeförsäkringen i världen (Edebalk 1996). Olycksfallsförsäkringen omfattade i stort sett alla löntagare och den finansierades med arbetsgivaravgifter. Ersättningen byggde på inkomstbortfallskompensation alltså att den skadedrabbade skulle få en ersättning som är relaterad till den lön som förloras på grund av arbetsskadan.

Medan regeringen förberedde lagen om olycksfallsförsäkring insåg man att det behövdes en allmän sjukförsäkring för att 
ta hand om kortare olycksfall och för att snabbt ge ersättning innan det hade konstaterats om det var en arbetsskada eller inte. Redan år 1915 tillsattes en ny utredning, som presenterade ett enhälligt förslag om en allmän sjukförsäkring år 1919 (Socialförsäkringskommittén 1919). Den frivilliga sjukförsäkring som fanns vid den här tiden hade en liten omfattning och det fanns över 1000 sjukkassor i Sverige. Förslaget innebar att det endast skulle finnas en sjukkassa per kommun, att ersättning skulle utgå enligt inkomstbortfall så att samordning kunde ske med olycksfallsförsäkringen samt att försäkringen i huvudsak skulle finansieras med egenavgifter. Några omedelbara positiva effekter av utredningen visade sig emellertid inte, främst p.g.a. den svåra deflationskris som bröt ut alldeles i början av 1920-talet och en härefter fortsatt hög arbetslöshet under mellankrigstiden. År 1931 genomfördes en partiell reform och monopolsjukkassor infördes. Denna reform innebar att sjukkasserörelsen effektiviserades men också att man administrativt ställde sig redo för en framtida obligatorisk sjukförsäkring. Först år 1955 kunde emellertid en allmän och obligatorisk sjukförsäkring införas i Sverige. Den byggde till sina huvuddrag på 1919 års förslag (Edebalk 1996).

Den allmänna pensionsförsäkringen gav också förutsättningar för en reformerad fattigvård och 1918 beslutades om en ny mer human fattigvårdslag (Proposition 1918:135). En viktig nyhet i den lagen var att kommunerna måste ha ålderdomshem och det var då som Sverige fick en särskild åldringsvård även om den först efter andra världskriget kom att omfatta alla behövande åldringar och inte bara fattiga.

\section{Avslutande synpunkter}

Den allmänna pensionsförsäkringen, som beslutades 1913, var principiellt viktig. Beslutet hade tagits med stor majoritet och det representerade början på ett socialpolitiskt systemskifte i Sverige. En modern yrkesskadeförsäkring beslutades ett par år senare och ett enhälligt förslag till allmän sjukförsäkring låg färdigt 1919. Socialförsäkringen var på väg att påtagligt reducera fattigvårdssystemets betydelse. Det nya systemet var universellt och innehöll inkomstbortfallskompensation och samordning, alltså ingredienser som brukar tillskrivas"den svenska modellen".

De grundstommar, som skapas i ett uppbyggnadsskede, har en tendens att bli långlivade. Exempelvis den tyska socialförsäkringsmodellen bär på spår av Bismarcks reformer på 1880-talet och den brittiska grundtrygghetsmodellen kan härledas till beslut, som fattades några år före första världskriget. Den svenska modellen växte fram i en svensk miljö, som bl.a. kännetecknades av en snabb industrialisering, arbetarrörelsens frammarsch och sociala spänningar. Till miljön hörde också en stor agrar sektor, en stor andel åldringar och en socialpolitik som i mångt och mycket bestod av en stigmatiserande kommunal fattigvård. Många småkommuner hade en svår försörjningssituation och frågan om finansiellt stöd till de fattigaste kommunerna hade kommit upp på den politiska dagordningen. Mot denna bakgrund kan 1913 års pensionsförsäkring ses som en del i politiken att utjämna utgifter mellan kommunerna. 


\section{Referenser}

Andersson, Lars (1995) Kommunalskattefrågan under mellankrigstiden. Skatterättvisa i och mellan kommuner. Lund: Lund University Press.

Baldwin, Peter (1990) The Politics of Social Solidarity. Class Basis of the European Welfare State 1875-1975. Cambridge: Cambridge University Press.

Berge, Anders (1995) Medborgarrätt och egenansvar. De sociala försäkringarna i Sverige 19011935. Lund: Arkiv.

Borg, Per (2004) Systemskifte. En studie av tröghet vid fyra brytpunkter inom svensk välfärdspolitik. Stockholm: Almqvist \& Wiksell International.

Edebalk, Per Gunnar (1996) Välfärdsstaten träder fram. Svensk socialförsäkring 1884-1955. Lund: Arkiv.

Edebalk Per Gunnar \& Olsson Mats (2011) Fattigvård, skatter och åldringsfrågan 1874 - 1913. Ett bidrag till framväxten av den svenska välfärdsstaten. Meddelande från Socialhögskolan 2011:1. Lund: Socialhögskolan.

Elmér, Åke (1960) Folkpensioneringen i Sverige. Lund: Gleerups.
Esping-Andersen, Gøsta (1985) Politics against Markets. Princeton: Princeton University Press. Håkansson, S-O (utg) (1952) Svenska valprogram I. Göteborg: Göteborgs universitet, Statsvetenskapliga institutionen.

Lundquist, Lennart (1997) Fattigvårdsfolket. Ett nätverk i den sociala frågan 1900 - 1920. Lund: Lund University Press.

Palmstierna, Erik (utg) (1907) Berättelse öfver förhandlingarna vid Kongressen för fattigvård och folkförsäkring i Stockholm den 4, 5 och 6 oktober 1906. Stockholm: Svenska boktryckeri.

Riksdagens protokoll jämte bihang

Sköld, Lars \& Halvarson, Arne (1966) "Riksdagens sociala sammansättning under 100 år". I Samhälle och riksdag. Stockholm: Almqvist \& Wiksell.

Socialförsäkringskommittén (1919) I. Betänkande och förslag angående allmän sjukförsäkring.

SOU 1925:8 Betänkande med utredning och förslag angående socialförsäkringens organisation.

Ålderdomsförsäkringskommittén (1912) I. Betänkande och förslag angående allmän pensionsförsäkring. 


\section{Summary}

\section{The Swedish Pension Insurance of 1913 - the first universal social insurance}

Around 1900 the only public measure of social policy for old people in Sweden was municipal poor relief. Some 75 per cent of the population lived in the countryside and Sweden had the oldest population in the known world, in relative terms. Many old and infirm people had to resort to the humiliation of letting poor relief provide for them. Several rural municipalities were afflicted by high expenses for poor relief.

Problems in the countryside, together with industrialization, were important factors behind the general pension insurance of 1913, which was the first universal social insurance in the world. The pension system consisted of two parts. One part was financed by individual contributions, and to this was added a supplementary tax-financed pension for those in need. This was supposed to ease the burden of municipal poor relief. The pension system was a compulsory one in which the individual contributions were related to a person's income, making them an earmarked tax. Thus general pension insurance became part of the general tax policy.

After the reform of 1913 income security came to be viewed as a social right for all, replacing the degrading system of poor relief. This was the first step towards the Swedish welfare state.

After the reform of 1913 income security came to be viewed as a social right for all, replacing the degrading system of poor relief. This was the first step in to the Swedish welfare state. 